\title{
Conceptualizing Perceived Benefits and Investigating Its Role in Adoption of Tablet Computers among Newspaper Subscribers
}

\author{
Jari Salo $^{1}$, Sami Kajalo ${ }^{2}$, Matti Mäntymäki ${ }^{3}$, and A.K.M. Najmul Islam ${ }^{3}$ \\ ${ }^{1}$ Oulu Business School, Oulu University, Finland \\ Jari.Salo@oulu.fi \\ ${ }^{2}$ Aalto School of Economics, Aalto University, Finland \\ Sami.Kajalo@aalto.fi \\ ${ }^{3}$ Turku School of Economics, University of Turku, Finland \\ \{Matti.Mantymaki,Najmul.Islam\}@utu.fi
}

\begin{abstract}
This paper conceptualizes perceived benefit as a combination of ecoconsciousness, social prestige, and extra services and proposes a research model for user acceptance of tablet computers. The model was tested among newspaper subscribers $(n=904)$ in one of the Nordic countries using Structural Equation Modeling (SEM).

The findings suggest that attitude toward tablet devices is predicted by ecoconsciousness, ease of use, social prestige, and extra services. In turn, attitude along with intention to use predict intention to buy. Furthermore, ease of use was also found to predict extra services.
\end{abstract}

Keywords: Attitude, eco-consciousness, intention to buy, perceived benefit, tablet computers, technology acceptance model.

\section{Introduction}

Due to the advent of smartphones and tablet devices, the publishing industry has been in turmoil. To respond to the challenge, new services and new business models have emerged. Altogether, this has changed the traditional industry logic [9, 8]. Services are offered to different types of mobile devices e.g. tablet computers using digital technologies. For the publishing industry, digital technologies and mobile services provide both opportunities and challenges to excel in their business [40].

Since the 1990s newspaper publishers have felt pressured to have a web presence to be competitive on the market $[9,18]$. Most players in the newspaper industry are either providing a replicate of its paper based newspaper or a modified version online [25]. One of the main reasons for the popularity of online newspapers is the possibility to utilize different technologies such as audio, graphics, video and interactive elements that are not possible to implement in a print version. For readers, on the other hand, interactive elements mean freedom to filter news according to their own preferences and the opportunity to give feedback on the articles, which creates a feeling of empowerment [37]. 
The digital publishing market is expanding rapidly and new players such as the Daily have entered the newspaper market. Moreover, buying content online is increasing among consumers altogether fundamentally changing the way people consume newspapers. To understand the phenomena related to the diffusion (see Rogers, 2005 [34]) of tablet devices, it is essential to what drives the user acceptance.

As users of tablet devices are consuming increasing amount e-books and other mobile digital services, it is important to understand of tablet devices in order to accelerate their diffusion in the market [34]. Tablet devices are capable to offer several material and social benefits such as elevated social status, eco-friendly reading experience, and rich online content [8, 25]. Consequently, this research attempts to address the following research question:

How perceived benefit does influence the decision to adopt a tablet computer for reading?

User acceptance of tablet devices is an interesting research area because of the changing newspaper consumption patterns that urges the publishing industry publishers to identify new business opportunities.

In this study, we investigate the user acceptance of tablet devices using the Technology Acceptance Model (TAM) [11, 12] as a theoretical foundation for how different aspects of technology acceptance and features of tablet devices impact consumers' willingness to adopt these devices.

The paper proceeds as follows. In section 2 we present the theoretical background and develop the research model. Section 3 is dedicated to the data collection and data analysis methods. Section 4 presents a discussion on the data analysis findings and concludes with the implications and limitations as well as suggestion for further inquiry.

\section{Theoretical Background and Research Model}

\subsection{Technology Acceptance Model}

The Technology Acceptance Model [11] has been the most influential and most widely applied model for explaining users' intention regarding IT use [21]. TAM was originally developed from Ajzen \& Fisbein's (1980) [1] theory of reasoned action (TRA).

TRA argues that if a person intends to commit a behavior it is likely that the person will actually do it. According to TRA, a person's behavioral intention depends on a person's attitude towards the behavior as well as the subjective norm [1]. Attitude is the combination of the user's beliefs about the consequences of performing the behavior and his or her evaluation of these consequences. The subjective norm is the combination of the relevant referents' expectations and the user's motivation to comply with these expectations.

TAM posits that perceived usefulness and perceived ease of use are the factors that determine an IS user's attitude, which, along with perceived usefulness, determines 
behavioral intention. Finally, behavioral intention determines actual IS use. Perceived usefulness is described as being directly influenced by perceived ease of use.

TAM has been validated across time, population, and contexts [43]. TAM is wellestablished in Information Systems research as well as other domains [21]. Venkatesh et al. (2007) [43] argues that TAM has become nearly a law-like model and that it often serves as a basis for studies in other areas. For example, TAM and its constructs have been used in areas outside technology adoption such as information adoption [39], marketing [10], and advertising [33].

Several studies have focused on acceptance of mobile devices, mobile services, mobile advertising, and tablet computer adoption using TAM as the theoretical lens $[8,27,35]$. Majority of the studies found that benefit captured through perceived usefulness as the most dominating factor to predict adoption [8, 9].

Despite TAM's popularity, it has a number of limitations as discussed by leading IS researchers $[4,7,17]$. Specifically, there are two limitations of prior TAM based studies that motivated us to conduct this study. First, perceived usefulness is regarded as black box with little research effort into investigating different dimensions of usefulness [4]. Hence, TAM studies often lack actionable guidance for practitioners. Second, TAM assumes that more use is better and consequently TAM based studies focused on intention to use. In other words, more utilization of a technology increases purchasing. However, only a few prior adoption studies verify a relationship between use and purchase [26].

\subsection{Conceptualizing Perceived Benefit}

Prior technology adoption research conceptualized perceived benefit by perceived usefulness [11, 26, 42]. Perceived usefulness is an indicator of the degree to which the use of an IS will enhance a user's job performance [11]. Most of the prior studies ignored the uniqueness of research context and modeled perceived usefulness as a black-box focusing on an overall benefit of an IS [8, 44].

Many of the contemporary tablet devices can be used for other purposes than reading, including surfing the web, playing games and using social media applications which are here labeled as extra services. As argued in prior studies [6], the usage context of the IT artifact and the users [23] are important factors in explaining the adoption behaviors. As a result, in the present study we specifically focus on opening the perceived benefit and investigate its role in predicting the acceptance of tablet devices.

In the present study, we employ user's eco-consciousness, the social prestige, and extra services offered by the tablet devices in order to conceptualize perceived benefit. We employ these three benefits to conceptualize perceived benefit as these were argued as important in prior research [25]. Eco-consciousness is defined as the extent to which the consumer perceives using a tablet device as an ecological choice. Social prestige is defined as the degree to which use of the tablet devices is perceived to enhance one's status in his/her social system. Finally the construct, extra services is defined as the degree to which the tablet devices provide facilities to acquire additional information in a particular topic of interest. 


\subsection{Hypotheses Development}

Figure 1 presents the hypothesized research model.

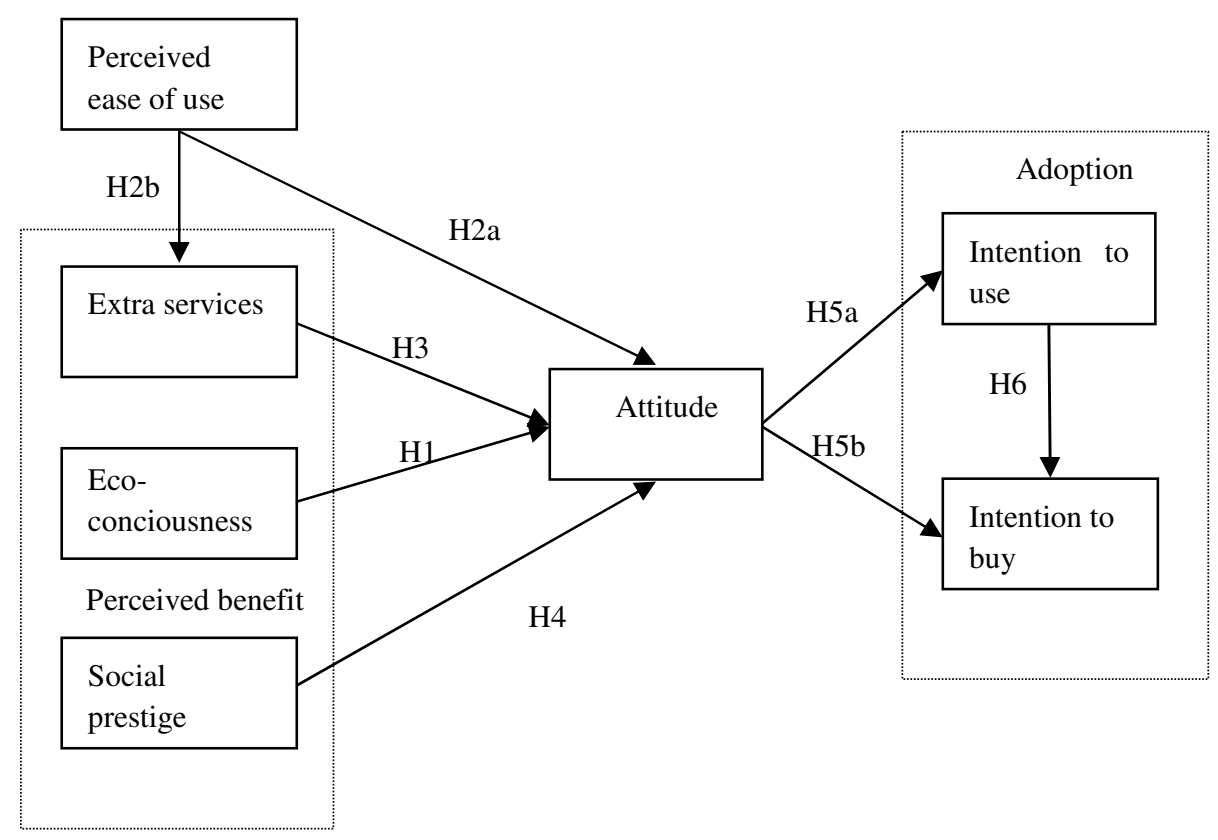

Fig. 1. Research model

Various environmental concerns are becoming increasingly prevalent and people tend to have more positive attitudes towards products that they perceive environmentally friendly [45]. Moberg et al. (2010) [25] found that using a tablet computer to read magazines and newspaper instead of having printed copies, the users may contribute to the environmental improvement. Following this finding, we expect that the users who perceive tablet devices as eco-friendly would have more positive attitude toward adopting a tablet device. In fact, eco-conscious users would avoid printed materials and prefer reading from the tablet screen. Prior research also argued that eco-friendly products can be considered status symbols and hence consumers are expected to have more positive attitude toward tablet devices [29]. As a result, we postulate the following hypotheses:

H1: Eco-consciousness is positively related to attitude towards using a tablet device.

According to TAM, we have positioned perceived ease of use as a predictor of attitude [11]. Perceived ease of use is defined as the degree to which a person believes that using a particular system would be free from effort [11]. Furthermore, it is plausible to assume that perceived ease of use determines how well the users can utilize the extra services of tablet devices [28]. Research on technology acceptance found that the extended use of an IS depends on the ease of use [19, 20]. Following 
this, it can be argued that if a tablet device is easy to use, the users will use it for a wide variety of purposes. Conversely, if the tablet devices offer a lot of additional functionalities with a difficult interface, the users would hardly try to explore the additional functionalities. Instead they would prefer to use only the basic features. Thus, the hypotheses related to the role of perceived ease of use are postulated as follows:

$\mathrm{H} 2 \mathrm{a}$ : Ease of use is positively related the attitude towards tablet devices.

$\mathrm{H} 2 \mathrm{~b}$ : Ease of use is positively related to extra services that tablet devices provide.

In reading books, newspapers and magazines, table devices offer several value-added features compared to the paper format. For example, articles can include links to complementary material e.g. audio, videos. Additionally, compared to traditional books and newspapers, tablet devices enable storing large amounts of material in a portable format so that the users can view the content at a later stage if they wish. Furthermore, the interesting news can be shared in the social media. Thus, we assert that these features of the tablet devices offer a major utility for the users and consequently positively affect the attitude towards using the device.

H3: Extra services are positively related to attitudes towards using a tablet device.

Attitudes do not develop in a vacuum but are influenced by e.g. other people's opinions, advertising and mass media [15]. As the diffusion of tablet computers has not proceeded into the late adopters and laggards stage, the use tablet computers can encompass certain status value for some users [34]. Prior technology adoption research has found image, which is similar to social prestige as a major driver of technology adoption [24, 42]. Thus we form the following hypothesis:

H4: Social prestige is positively related to the attitudes towards using a tablet device.

We argue that the actual adoption of a tablet device consists of two behaviors, usage and purchasing. Most prior research has investigated usage as the sole construct that reflect adoption [21, 44]. We argue that usage provides only a limited view of adoption. For example, many consumers may have the opportunity to use a tablet device owned by their family member of employer. They may or may not intent to buy a tablet device for his personal use. Thus, it is necessary to investigate both usage and purchase intention to understand tablet devices adoption. With this aim, we employed both use intention and buying intention in our research model.

Given that using a tablet device generally requires purchasing one, usage and purchasing can be viewed closely related behaviors with regard to the utilization of tablet devices. Grounded on TRA, TAM views behavioral intention being determined by attitudes [11]. As a result, we assert that attitude towards using a tablet device predicts both the use intention and purchasing intention.

H5a: Attitude towards using a tablet device is positively related to the intention to use a tablet device.

H5b: Attitude towards a tablet device is positively related to intention to buy a tablet device. 
Finally, we argue that the two behavioral intentions, using a tablet device and purchasing one are related so that the use intention precedes purchasing. The argumentation is grounded on the assumption that process wise the willingness to use a shared (e.g., employer or family) tablet device would influence the users to buy their own devices at a later stage in order to fulfill a set of needs that takes place by using the device. Thus, we hypothesize the following:

H6: Intention to use a tablet device is positively related to intention to buy a tablet device.

\section{Study Design and Method}

\subsection{Data Collection}

The questionnaire was developed in several phases. First, the items of the questionnaire were developed on the basis of the literature review. Second, these questions were further developed after conducting several focus groups interviews among university students. Third, the item pool was pre-tested by sending the web survey to 200 newspaper subscribers. $23.5 \%$ of them answered the questionnaire and gave feedback that was used in developing the final questionnaire.

The data was collected through an internet survey in October 2010 among subscribers of a daily newspaper from one of the Nordic countries. It is a nationwide daily newspaper with long tradition and high standard of journalism. The link to the final questionnaire was sent by e-mail to 5000 subscribers of the newspaper. After one remainder e-mail 1084 out of 5000 respondents had answered the survey. Given the length of the web survey we find the response rate of $21.7 \%$ satisfactory. After filtering the incomplete responses, we ended up with 904 usable responses.

We consider the respondents represented well the subscribers of the newspaper. There were 454 male respondents and 450 female respondents, and thus there was a balance in terms of gender Moreover, no significant differences in means were found between early and late respondents on the scales studied (t-tests at .05 level), indicating that a non-response bias is unlikely to be a problem [3].

All measures in this study were collected via a single questionnaire, which opens up the threat of common method bias. Common method variance can either inflate or deflate observed relationships between constructs [31, 32]. We used the Harman's one-factor test to address this issue [32]. If a substantial amount of common method variance is present, either a single factor will emerge from the factor analysis, or one dominant factor will account for the majority of the covariance among the variables. All the items were entered into an exploratory factor analysis, using principal component analysis with varimax rotation. No dominant factor emerged which indicates the common method bias is not present in this study. The list of final measurement items in each scale of the inquiry is presented in Appendix 1. 


\subsection{Data Analysis}

Structural equation modeling (SEM) technique has been used to test the hypothesized research model. SEM is particularly suitable for testing the proposed theoretical model, because it allows simultaneous estimation of multiple relationships between observed and latent constructs, and account for measurement error. Thus, we are able to test an overall model rather than just coefficients individually [5].

We used a two-step SEM approach in accordance with Anderson \& Gerbing (1988) [2]. First, a confirmatory factor analysis (CFA) assessing the validity of the measurement model and the discriminant validity of the individual constructs was conducted. Second, a structural model is used to estimate the path coefficients and test for the relationships between constructs.

Following Anderson \& Gerbing (1988) [2], CFA was carried out to assess the validity of all the construct measures included in this study. This assessment was carried out using LISREL 8.80 program. The fit of the measurement model was evaluated based on several goodness-of-fit indicators. These were the chi-square statistic $(\chi 2)$, root mean square error of approximation (RMSEA), goodness of fit index (GFI), non-normed fit index (NNFI), and comparative fit index (CFI). RMSEA is usually regarded as the most informative of the fit indices, and values less than .08 are indicative of reasonable fit [36]. GFI is an absolute fit index, whereas NNFI and CFI are relative indices. For all three, values above .90 indicate good fit $[36,38]$. The model under consideration provided good fit $(\chi 2=813.11 ; \mathrm{df}=188 ; \mathrm{p}=.000$; RMSEA=.055; GFI=.94; NNFI=.98; CFI=.98).

In order to evaluate the reliability of the latent variables, composite reliability values and average variance extracted values for each latent variable were calculated [13]. These are reported in Table 1 together with means and standard deviations for the scales, and the correlation matrix. They all exceeded the recommended level of 0.70 (ranging from 0.84 through 0.98 ). Likewise, average variance extracted values exceeded the recommended level of 0.50 (ranging from 0.57 through 0.92 ). Also, all factor loadings were statistically significant at the $5 \%$ level, and all of the factor loadings exceed the 0.50 level (ranging from 0.65 through 0.98) [16]. To conclude, our measures demonstrate adequate convergent validity.

Table 1. The scale means, standard deviations, reliability indexes and correlation matrix

\begin{tabular}{|l|c|c|c|c|c|c|c|c|c|c|}
\hline \multicolumn{1}{|c|}{ Construct } & Mean & S.D. & $\rho_{\mathrm{c}}$ & $\rho_{\mathrm{v}}$ & 1 & 2 & 3 & 4 & 5 & 6 \\
\hline Eco-consciousness & 3.58 & 1.72 & .98 & .92 & 1.00 & & & & & \\
\hline Ease of use & 5.00 & 1.40 & .92 & .76 & $.11^{*}$ & 1.00 & & & & \\
\hline Extra services & 3.47 & 1.04 & .84 & .57 & $.22^{*}$ & $.28^{*}$ & 1.00 & & & \\
\hline Social prestige & 1.59 & 0.94 & .91 & .78 & $.15^{*}$ & -.04 & $.11^{*}$ & 1.00 & & \\
\hline Attitude & 3.94 & 1.66 & .91 & .77 & $.25^{*}$ & $.35^{*}$ & $.50^{*}$ & $.23^{*}$ & 1.00 & \\
\hline Intention to use & 4.45 & 1.83 & .94 & .73 & $.22^{*}$ & $.38^{*}$ & $.51^{*}$ & $.12^{*}$ & $.77^{*}$ & 1.00 \\
\hline Intention to buy & 2.76 & 1.64 & .84 & .67 & $.19^{*}$ & $.30^{*}$ & $.38^{*}$ & $.23^{*}$ & $.65^{*}$ & $.65^{*}$ \\
\hline
\end{tabular}

S.D.: standard deviation, $\rho_{\mathrm{c}}$ : composite reliability, $\rho_{\mathrm{v}}$ : average variance extracted. $\rho_{\mathrm{c}}$ : $\left(\sum \lambda\right)^{2} /\left(\left(\sum \lambda\right)^{2}+\sum(\theta)\right)$

$\rho_{\mathrm{v}}$ : $\left(\sum \lambda\right)^{2} /\left(\sum \lambda^{2}+\sum(\theta)\right), \lambda$ : indicator loading, $\theta$ : indicator error variance. $*=$ correlation is significant at .01 level (2-tailed). 
The hypothesized model testing was undertaken by deploying covariance matrix and the maximum likelihood estimation procedure. Overall, the fit indexes $\left(\chi^{2}=959.27 ; \mathrm{df}=199 ; \mathrm{p}=.000 ; \mathrm{RMSEA}=.059 ; \mathrm{GFI}=.93 ; \mathrm{NNFI}=.97 ; \mathrm{CFI}=.98\right)$ imply a good model fit. Figure 2 illustrates the final structural model with standardized path estimates and $\mathrm{t}$-values.

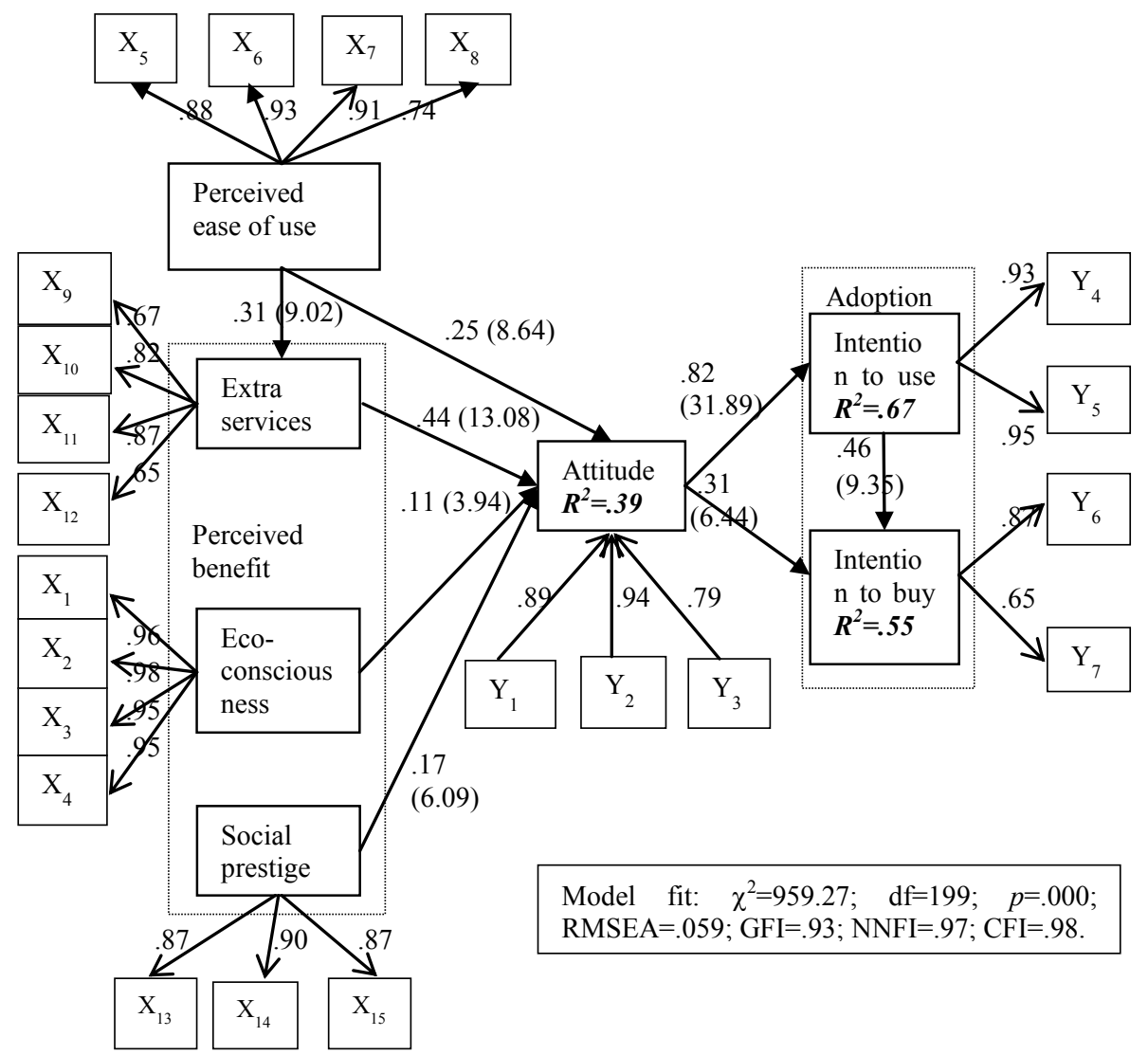

Fig. 2. SEM results

Figure 2 shows that Eco-consciousness is positively related to attitude $(\beta=.11)$ created by tablet devices. These results provide empirical evidence for Hypothesis H1. However, these relations are rather weak.

Perceived ease of use is positively related both to attitudes towards tablet devices $(\beta=.25)$ and extra services $(\beta=.31)$ that tablet devices provide. These relationships are strong, and thus, strong empirical evidence for our hypotheses $\mathrm{H} 2 \mathrm{a}$ and $\mathrm{H} 2 \mathrm{~b}$ is provided.

Also hypothesis H3 was supported, as extra services provided by tablet devices had a very strong positive influence on the attitudes towards tablet devices $(\beta=.44)$. A weak relationship exists between social prestige created by tablet devices and the 
attitudes towards tablet devices: the path coefficient was found at $\beta=.17$, supporting our hypothesis H4. Finally, the attitudes towards tablet devices is positively related to intention to use $(\beta=.82)$ tablet device, and the intention to buy $(\beta=.31)$ a tablet device. Also, as expected there was a strong direct relationship from intention to use to intention to buy $(\beta=.46)$ a tablet device. These findings provide support for the hypotheses $\mathrm{H} 5 \mathrm{a}, \mathrm{H} 5 \mathrm{~b}$ and $\mathrm{H} 6$ respectively. To conclude, all our hypotheses received empirical support.

The explanatory power of the path model for each depended construct was examined by using $\mathrm{R}^{2}$ values. These were 10 percent for extra services, 39 percent for the attitudes towards tablet devices, 67 percent for intention to use and, finally, 55 percent for intention to buy a tablet device.

To summarize, we found empirical evidence for all the hypotheses. The results suggest that ease of use and extra services that tablet computers provide are key elements when consumers develop attitude toward these devices. While ecological values and social prestige were found to have statistically significant impact on attitude, they were not as important as the ease of use and extra services that these devices provide.

\section{Discussions}

\subsection{Main Findings}

All of the proposed hypotheses were empirically supported. First, we found that all three constructs: eco-consciousness, social prestige, and extra services have significance influence on attitude. The relationship between eco-consciousness and attitude implies that environmental conscious users are likely to justify their immediate action based on their environmental knowledge [30]. However, it is interesting to observe that eco-consciousness was found to be a weak contributor in the adoption of tablet devices. This results suggest that users do not possess enough knowledge how using tablet computers for reading brings the environmental benefits.

The relationship between social prestige and attitude implies that tablet devices are regarded as status symbols. Prior technology adoption research used image as a variable focusing one's status symbol [24, 42]. Venkatesh \& Davis (2000) [42] argued that the elevated social status provides a general basis for greater productivity. Following this line of argument, it is logical that social status influences the attitude toward using tablet devices. Thus, our finding is in line with prior literature.

It is interesting to observe that extra services played the strongest role in shaping users' attitude toward using tablet devices. This finding is supported by the media richness theory [14] which suggests a particular communication medium is preferred over another depending on the capability of the medium and users' task requirement. The online versions of newspapers definitely provide content in much richer format (e.g., videos, photos, hyperlinks) than that the printed versions. Thus, consumers consider the extra services as most important factor in order to develop their attitude toward the adoption of tablet computers. 
Second, we found that perceived ease of use has significant influence on both extra services and attitude. The relationship between perceived ease of use and attitude is in line with the TAM tradition [11]. The relationship between perceived ease of use and extra services suggest that consumers choose to use the extra services only when the tablets are easy to use. This finding was not tested empirically in prior literature. However, some evidences can be drawn from the prior literature in support to this finding. For example, Hossain (2012) [19] found that many features of a complex information system often remain underutilized. Thus, it is expected that perceived ease of use would lead consumers use the extra services offered by the tablet devices.

Finally, we found that intention to use is predicted by attitude. This relationship is in line with the TAM tradition [11]. Furthermore, we found that both attitude and intention to use have significant influence on intention to buy a tablet device. In fact, it is interesting to observe that intention to use has the strongest influence on intention to buy. This result implies that consumers are more likely to purchase a tablet device if they would get a chance to use it beforehand.

\subsection{Implications}

Our research study has the following two major theoretical contributions. First, the study addresses how different aspects of technology acceptance and features of tablet devices impact consumers' willingness to adopt tablet devices. Given that tablet computers and dedicated e-reading devices are becoming increasingly popular, the present study makes a contribution to the research on the adoption of these technologies.

Second, we have conceptualized perceived benefit into three parts: ecoconsciousness, social prestige, and extra services in the tablet computer adoption context. We have empirically tested the relationships of these variables with attitude toward using tablet devices. While most prior adoption research conceptualized perceived benefit as an overall benefit of using a system (i.e., perceived usefulness), our conceptualization and subsequent analysis sheds light on which benefit actually motivates consumers to adopt tablet devices for e-reading.

Our study findings have practical implications for tablet manufacturers and newspaper publishers. First, we found that eco-consciousness played a significant role for tablet adoption. Thus, the manufacturer needs to bring up the green values of using tablet computers for reading and avoiding printed media. As we found the influence of eco-consciousness on attitude as weak, we suggest manufacturer on describing how the tablet devices are eco-friendly in their marketing campaign.

Second, for newspaper industry, we recommend that only those devices that are easy-to-use are utilized as the main channel for content distribution. It might be that general tablet devices like iPad and Samsung Galaxy are most prominent for newspapers which have also color full content and can utilize embedded videos while single purpose devices such as Amazon Kindle could be more suitable for just ereading.

For tablet device manufacturers it seems that easy-of-use is still the most important feature and to be aimed for. Furthermore, the role of tablet devices as ways for 
reducing utilization of paper could be used as value based selling arguments in ads and marketing communication.

\subsection{Limitations and Future Research}

Our research has two major limitations that however also offer avenues for future research. First, the research was cross-sectional. The beliefs of the users regarding a system will change as the users gain experience of a target system but such changes cannot be captured with the type of cross-sectional study undertaken.

Second, our empirical analysis did not consider possible cultural differences, and different types of newspapers and magazines (e.g. local versus. national newspapers). Furthermore, we did not distinguish between different devices or operating systems (e.g. iPads vs. Android). Hence, we encourage empirical studies taking a comparative approach.

Third and finally, we did not examine the influence of price. Given that price is a key factor in setting the level of demand [44], future research incorporating the pricing of the newspaper and the potential value-added features would be managerially highly relevant.

\section{References}

1. Ajzen, J., Fishbein, M.: Understanding attitudes and predicting social behavior. PrenticeHall, Englewood Cliffs (1980)

2. Anderson, J.C., Gerbing, D.W.: Structural equation modeling in practice - a review and recommended 2-step approach. Psychological Bulletin 103(3), 411-423 (1988)

3. Armstrong, J.S., Overton, T.S.: Estimating non-response bias in mail surveys. Journal of Marketing Research 14(3), 396-402 (1977)

4. Bagozzi, R.R.: The legacy of the technology acceptance model and a proposal for a paradigm shift. Journal of the Association of Information Systems 8(4), 244-254 (2007)

5. Bagozzi, R.P., Yi, Y.: Specification, evaluation, and interpretation of structural equation models. Journal of the Academy of Marketing Science 40(1), 8-34 (2012)

6. Benbasat, I., Zmud, R.W.: The identity crisis within the IS discipline: Defining and communicating the discipline's core properties. MIS Quarterly 27(2), 183-194 (2003)

7. Benbasat, I., Barki, H.: Quo vadis, TAM? Journal of the Association of Information Systems 8(4), 211-218 (2007)

8. Chen, S., Granitz, N.: Adoption, rejection, or convergence: Consumer attitudes toward book digitization. Journal of Business Research 65(8), 1219-1225 (2012)

9. Colleen, P.K., Chiagouris, L., Gopalkrishna, P.: Some people just want to read: The roles of age, interactivity, and perceived usefulness of print in the consumption of digital information products. Journal of Retailing and Consumer Services 19, 168-178 (2012)

10. Dabholkar, P.A., Bagozzi, R.P.: An attitudinal model of technology-based self-service: Moderating effects of consumer traits and situational factors. Journal of Academy of Marketing Science 30(3), 184-201 (2002)

11. Davis, F.D.: Perceived usefulness, perceived ease of use, and user acceptance of information technology. MIS Quarterly 13(3), 319-340 (1989) 
12. Davis, F.D., Bagozzi, R.P., Warshaw, P.R.: User acceptance of computer technology: A comparison of two theoretical models. Management Science 35(2), 982-1003 (1989)

13. Diamantopoulos, A., Siguaw, J.A.: Introducing LISREL: A guide for the uninitiated. Sage Publications, London (2000)

14. Daft, R.L., Lengel, R.H.: Organizational information requirements, media richness and structural design. Management Science 32(5), 554-571 (1986)

15. Entman, R.: How the media affect what people think: An information processing approach. The Journal of Politics 51(2), 347-370 (1989)

16. Fornell, C., Larcker, D.F.: Evaluating structural equation models with unobservable variables and measurement error. Journal of Marketing Research 18(1), 39-50 (1981)

17. Goodhue, D.L.: Comment on Benbasat and Barki's "Quo vadis TAM" article. Journal of the Association of Information Systems 8(4), 219-222 (2007)

18. Greer, J.D., Mensing, D.: The evolution of online newspapers: A longitudinal content analysis, 1997-2003. In: Li, X. (ed.) Internet Newspapers: The Making of a Mainstream Medium, pp. 13-32. Lawrence Erlbaum Associates, New Jersey (2006)

19. Hossain, M.A.: Adoption, continued, and extended use of radio frequency identification (RFID) technology: Australian Livestock Industry, Doctoral dissertation, Curtin University, Australia (2012)

20. Hsieh, J.J.P., Wang, W.: Explaining employee's extended use of complex information systems. European Journal of Information Systems 16(3), 216-227 (2007)

21. Lee, Y., Kozar, K.A., Larsen, K.: The technology acceptance model: Past, present, and future. Communications of the Association for Information Systems 12, 752-780 (2003)

22. Mathieson, K.: Predicting user intentions: comparing the technology acceptance model with the theory of planned behavior. Information Systems Research 2(3), 173-191 (1991)

23. Moon, J.W., Kim, Y.G.: Extending the TAM for a world wide web contex. Information \& Management 38(4), 217-230 (2001)

24. Moore, G.C., Benbasat, I.: Development of an instrument to measure the perception of adopting an information technology innovation. Information Systems Research 2(3), 192$222(1991)$

25. Moberg, Å., Johansson, M., Finnveden, G., Jonsson, A.: Printed and tablet e-paper newspaper from an environmental perspective: A screening life cycle assessment. Environmental Impact Assessment Review 30, 177-191 (2010)

26. Mäntymäki, M.: Continuous use and purchasing behavior in social virtual world, Doctoral dissertation, Turku School of Economics, Turku, Finland (2011)

27. Nysveen, H., Pedersen, P.E., Thorbjørnsen, H.: Intentions to use mobile services: Antecedents and cross-service comparisons. Journal of the Academy of Marketing Science 33(3), 330-346 (2005a)

28. Nysveen, H., Pedersen, P.E., Thorbjornsen, H., Berthon, P.: Mobilizing the brand: the effects of mobile services on brand relationships and main channel use. Journal of Service Research 7(3), 257-276 (2005b)

29. Ottman, J., Stafford, E., Hartman, C.: Avoiding green marketing myopia: Ways to improve consumer appeal for environmentally preferable products. Environment: Science and Policy for Sustainable Development 48(5), 22-36 (2006)

30. Pelletier, L.G.: A motivational analysis of self-determination for pro-environmental behavior. In: Deci, E.L., Ryan, R.M. (eds.) Handbook of Self-Determination Research. The University of Rochester Press, NY (2002)

31. Podsakoff, P.M., MacKenzie, S.B., Lee, J., Podsakoff, N.P.: Common method biases in behavioral research: A critical review of the literature and recommended remedies. The Journal of Applied Psychology 88(5), 879-903 (2003) 
32. Podsakoff, P.M., Organ, D.W.: Self-reports in organizational research: Problems and prospects. Journal of Management 12(2), 531-544 (1986)

33. Rodgers, S., Chen, Q.M.: Post-adoption attitudes to advertising on the internet. Journal of Advertising Research 42(5), 95-104 (2002)

34. Rogers, E.: Diffusion of Innovations. Free Press, New York (2005)

35. Scharl, A., Dickinger, A., Murphy, J.: Diffusion and success factors of mobile marketing. Electronic Commerce Research and Applications 4(2), 159-173 (2005)

36. Sharma, S., Mukerjee, S., Kumar, A., Dillon, W.R.: A simulation study to investigate the use of cutoff values for assessing model fit in covariance structure models. Journal of Business Research 58(7), 935-943 (2005)

37. Spyridou, P., Veglis, A.: Exploring structural interactivity in online newspapers: A look at the Greek web landscape. First Monday 13(5), 1-10 (2008)

38. Steenkamp, J.-B.E.M., van Trijp, H.C.M.: The use of LISREL in validating marketing constructs. International Journal of Research in Marketing 8(4), 283-299 (1991)

39. Sussman, S.W., Siegal, W.S.: Information influence in organizations: An integrated approach to knowledge adoption. Information Systems Research 14(1), 47-65 (2003)

40. Tian, X., Martin, B., Deng, H.: The impact of digitization on business models for publishing: Some indicators from a research project. Journal of Systems and Information Technology 10(3), 232-250 (2008)

41. Trappey III, R.J., Woodside, A.G.: Consumer Responses to Interactive Advertising Campaigns - Coupling Short-Message-Service Direct Marketing and TV Commercials. Journal of Advertising Research 4(3), 382-401 (2005)

42. Venkatesh, V., Davis, F.D.: A theoretical extension of the technology acceptance model: four longitudinal field studies. Management Science 46(2), 186-204 (2000)

43. Venkatesh, V., Davis, F.D., Morris, M.G.: Dead or alive? The development, trajectory and future of technology adoption research. Journal of Association for Information Systems 8(4), 267-286 (2007)

44. Venkatesh, V., Thong, J.Y.L., Xu, X.: Consumer acceptance and use of information technology: Extending the unified theory of acceptance and use of technology. MIS Quarterly 36(1), 157-178 (2012)

45. Wati, Y., Koo, C.: Toward green IS adoption behaviors: A self-determination perspective. In: Proceedings of 45th Hawaii International Conference on System Sciences (HICSS), Hawaii, USA (2012) 


\section{Appendix 1. Survey Items Used to Measure Constructs and Scaling}

\begin{tabular}{|c|c|}
\hline $\begin{array}{l}\text { Eco- } \\
\text { consciousness }\end{array}$ & $\begin{array}{l}\text { I believe that using a tablet device is a good thing for the } \\
\text { environment }\left(\mathrm{X}_{1}\right) \\
\text { I believe that using a tablet device would be an eco-conscious } \\
\text { choice }\left(\mathrm{X}_{2}\right) \\
\text { I believe that using a tablet device would help to preserve natural } \\
\text { resources }\left(\mathrm{X}_{3}\right) \\
\text { By using a tablet device, I believe I could help the environment } \\
\left(\mathrm{X}_{4}\right)\end{array}$ \\
\hline Ease of use & $\begin{array}{l}\text { I believe a tablet device is easy to use }\left(X_{5}\right) \\
\text { I believe it is easy to get a tablet device to do what I want it to do } \\
\left(\mathrm{X}_{6}\right) \\
\text { I believe my interaction with a tablet device would be clear and } \\
\text { understandable }\left(\mathrm{X}_{7}\right) \\
\text { I believe that using a tablet device does not require a lot of my } \\
\text { mental effort }\left(\mathrm{X}_{8}\right)\end{array}$ \\
\hline Extra services & $\begin{array}{l}\text { Possibility to watch news videos }\left(\mathrm{X}_{9}\right) \\
\text { Get more information on certain factors in a news article by } \\
\text { clicking the words }\left(\mathrm{X}_{10}\right) \\
\text { Possibility to see more picture material of certain news }\left(\mathrm{X}_{11}\right) \\
\text { Possibility to save interesting articles into an article bank on a } \\
\text { tablet device }\left(\mathrm{X}_{12}\right)\end{array}$ \\
\hline Social prestige & $\begin{array}{l}\text { Using a tablet device would help me feel accepted }\left(\mathrm{X}_{13}\right) \\
\text { Using a tablet device would improve the way I am perceived } \\
\left(\mathrm{X}_{14}\right) \\
\text { The use of a tablet device would give its owner social approval } \\
\left(\mathrm{X}_{15}\right)\end{array}$ \\
\hline Attitude & $\begin{array}{l}\text { Using a tablet device would be interesting }\left(\mathrm{Y}_{1}\right) \\
\text { I would have fun using a tablet device }\left(\mathrm{Y}_{2}\right) \\
\text { The use of a tablet device would give me pleasure }\left(\mathrm{Y}_{3}\right)\end{array}$ \\
\hline $\begin{array}{l}\text { Intention } \\
\text { use }\end{array}$ & $\begin{array}{l}\text { Given that I had a tablet device, I predict I would use it }\left(\mathrm{Y}_{4}\right) \\
\text { Assuming a tablet device would be available for me I intend to } \\
\text { use it }\left(\mathrm{Y}_{5}\right)\end{array}$ \\
\hline $\begin{array}{l}\text { Intention } \\
\text { buy }\end{array}$ & $\begin{array}{l}\text { I intend to purchase a tablet device in the short term }\left(\mathrm{Y}_{6}\right) \\
\mathrm{I} \text { intend to purchase a tablet device in } 5 \text { years }\left(\mathrm{Y}_{7}\right)\end{array}$ \\
\hline
\end{tabular}

The response options ranged from 1 , "totally disagree" to 7 , "totally agree" 